\title{
Entre obsesiones y subjetividades, el cine de autor de Hayao Miyazaki
}

\author{
Alfonso Ortega Mantecón ${ }^{1}$
}

\section{Resumen}

Al momento de hablar del cine de autor - tal y como esta teoría fue propuesta por François Truffaut y André Bazin, entre otros teóricos-, se confiere al cineasta o director el papel de máxima autoridad creativa entre los implicados en una producción. De esta manera, los filmes pasarán a ser construcciones enteramente subjetivas y manifestaciones directas de las preocupaciones, temáticas y obsesiones del cineasta; pudiendo hablar así de la existencia de un sello característico que predomina a lo largo de su filmografía o que se manifiesta a través de signos latentes y constantes en su obra. El presente artículo tiene como objetivo demostrar que la obra del realizador japonés Hayao Miyazaki, puede enmarcarse dentro del cine de autor. Para esto, se recuperan las ideas y principales postulados de la teoría del cine de autor, mismos que - matizados con sus respectivas críticas posmodernas - fungen como marco teórico y categorías de análisis al aproximarse a su filmografía Abstract

When talking about the film d'auteur —as this theory was proposed by François Truffaut and André Bazin, among other theorists-, the filmmaker is conferred the role of maximum creative authority among those involved in a production. The films become entirely subjective constructions and direct manifestations of the director's concerns, themes and obsessions; allowing to propose the existence of a characteristic seal that predominates throughout its filmography or that manifests itself through latent and constant signs in its work. This article aims to demonstrate that the work of the Japanese filmmaker Hayao Miyazaki can be framed within the auteur theory. For this, the ideas and main postulates of the theory of the author's cinema are recovered - nuanced with their respective postmodern critics - as theoretical framework and categories of analysis when approaching his filmography.

\section{Palabras Clave}

Cine, Teoría del cine de autor, Cine de Animación, Hayao Miyazaki

\section{Keywords}

Cinema, Auteur Theory, Animation Cinema, Hayao Miyazaki

${ }^{1}$ Universidad Autónoma Metropolitana

\section{Introducción}

La teoría del cine de autor - conformada por una serie de postulados, ideas, formulaciones, debates y críticas a los mismos-, pese a contar con más de cincuenta años de antigüedad, se encuentra vigente en la industria cinematográfica contemporánea, gozando de la atención tanto de la crítica especializada, como de los académicos e investigadores, así como de la audiencia misma.
En cierto modo, la concepción de algunos cineastas como autores se ha convertido, en las últimas décadas, en un sello o marca distintiva mediante la cual se busca promocionar y difundir el material del realizador (Roberts, 2018, p. 4). El hecho de que un filme sea anunciado como la nueva obra de Steven Spielberg, Tim Burton, Spike Lee, Quentin Tarantino o David Lynch, sirve al espectador y a la crítica como una preparación mental de lo que le espera antes del visionado de la respectiva película, todo esto tomando en consideración la 
peculiar y amplia trayectoria de estos directores, así como las fórmulas y esquemas constantes que se encuentran presentes dentro de sus respectivas filmografías.

El reconocer a determinados cineastas como autores ha sido, también, una estrategia mercadológica que se ha implementado con mayor fuerza en la industria cinematográfica desde la publicación de los primeros postulados que le conferían al realizador este título. El hecho de que se anuncie un filme como la nueva obra de un director o directora que ha logrado "pertenecer" a este selecto grupo, trae consigo una carga importante de expectativas, tanto de la crítica como de los seguidores del director, que se verá reflejada en la industria a través de grandes ingresos en taquillas, y al ocupar un puesto especial en la atención de la crítica especializada y en la misma agenda mediática. ${ }^{1}$

Dentro del grupo de cineastas que son considerados autores, es posible encontrar el predominio de aquellos que trabajan mediante la técnica de la acción real (live action); es decir, filmes en los que se hace uso de actores y de las técnicas convencionales de grabación mediante la utilización de cámaras, iluminación y otros recursos similares. En contraparte, los realizadores que emplean la técnica de la animación —en sus múltiples variables - no reciben, a menudo, la consideración como autores, pese a que en su obra y producción fílmica es posible encontrarse con las cualidades y características que han sido destacadas y exaltadas por los teóricos y críticos que propusieron la teoría del cine de autor.

En la industria de animación estadounidense, representada principalmente por los estudios Disney y Dreamworks, es posible encontrarse con una tendencia dictada por las necesidades económicas-industriales y empresariales de estos grandes emporios, hasta poder hablar de la existencia de un sello o marca distintiva otorgado por el mismo estudio, situación que sume al director en el anonimato, conduciéndolo a seguir una ruta preestablecida para la elaboración del

\footnotetext{
${ }^{1}$ Un caso particular contemporáneo que ejemplifica la expectativa que genera una obra cinematográfica más por su realizador que por su contenido per se es el del filme Tenet, la nueva película de Christopher Nolan a estrenarse en 2020 que ha sufrido numerosos cambios de fecha de estreno debido a la pandemia del Covid-19. Más allá de que las audiencias conozcan o anhelen ver en la gran pantalla la historia narrada en esta cinta, las expectativas se han situado del lado del autor, donde la reconocida trayectoria de Nolan dota al filme a estrenarse de un aura de calidad o de altas expectativas que anteceden al mismo visionado de la cinta, bajo la idea de que toda obra realizada por el cineasta es de calidad y sigue la misma línea planteada en su filmografía previa.
}

proyecto en cuestión. Esta situación se evidencia en los mismos eventos donde las compañías anuncian sus próximos estrenos en los años siguientes, tanto en ellos, como en las notas de prensa derivadas, se difunden los títulos de las cintas animadas que se encuentran en producción, así como los estudios —Pixar, por ejemplo en el caso de Disney- que estarán implicados en la realización del producto mediático, sin hacer énfasis o mención a quienes se encuentran a la cabeza del proyecto.

La situación varía considerablemente en el cine japonés de animación (anime), industria que tiene al Studio Ghibli como uno de sus principales representantes. A diferencia de la tendencia predominante en el territorio norteamericano, en Japón es posible hablar de la existencia de un cine de autor de animación que ha visto en Hayao Miyazaki, a un realizador que puede ingresar al selecto grupo de cineastas considerados autores.

El presente artículo tiene como objetivo demostrar, mediante la realización de un análisis a la trayectoria cinematográfica de Hayao Miyazaki, que el realizador japonés puede enmarcarse dentro del cine de autor. Para esto, en un primer apartado, se recuperarán las ideas y postulados principales de la teoría del cine de autor, mismos que - matizados con sus respectivas críticas y comentariosfungirán como marco teórico y categorías de análisis al aproximarse a la obra de este cineasta.

\section{Notas sobre la teoría del cine de autor}

La concepción del artista —ya sea pintor, escultor, escritor o cineasta - como un autor, forma parte del discurso habitual y cotidiano de la cultura popular contemporánea, pudiendo considerarlo, en ocasiones, como una institución cultural (Grant, 2008, p. 5) de referencia. Roland Barthes (1915-1980) considera al autor como una "figura moderna, producto de la misma sociedad" (1977, p. 142) en la que nace. Pero, ¿de qué sirve cuestionarse acerca de si determinado artista, cineasta en específico, puede ser considerado un autor? Con respecto a esto, David Tredge menciona que: "Estudiar el trabajo de los cineastas es una forma de mejorar el valor 
de producción de una película. En este sentido, el estudio y la aplicación de la teoría del cine también sustentarán y mejorarán una producción [...]. La teoría del cine de autor tiene dos objetivos: clasificar las películas y reconocerlas como obras de arte"(2013, pp. 6-7).

Para mediados del siglo $\mathrm{XX}$, los críticos y estudiosos europeos del cine buscaron aproximarlo aún más a las otras seis artes equiparando a algunos cineastas con escritores y pintores, al mismo tiempo que buscaron que ciertas obras pudieran aspirar a ser consideradas obras de arte, situación que abría posibilidades al cine a ser considerado como algo más que mero entretenimiento. Mientras que en las otras artes el debate de la originalidad autoral tuvo lugar en el siglo XIX (Gubern, 2005, p. 16), en el cine comenzaría hasta la década de los 50, siendo considerado una de las inflexiones que motivaron el paso del cine clásico al moderno. Específicamente, las discusiones se remontan a los debates, postulados e ideas provenientes de los directores y críticos de la revista francesa Cahiers $d u$ Cinéma en la década de los cincuenta, siendo François Truffaut (1932-1984) el primero en aproximarse al tema en su ensayo "Una cierta tendencia del cine francés", publicado en el número 31 (1954) de esta revista.

En este texto, el director de Los 400 golpes (Les quatre cents coups, 1959) centra su atención en la obra de los prolíficos guionistas franceses Jean Aurenche (1904-1992) y Pierre Bost (1901-1975), quienes trabajaron conjuntamente en numerosas e importantes películas a mediados del siglo XX. Truffaut considera a ambos guionistas los expositores de una tendencia que se encontraba presente dentro del cine francés, a la que denomina como "tradición de la calidad". Esta se caracteriza por el establecimiento de una ecuación en las producciones cinematográficas, dentro de la cual todos los elementos se encuentran perfectamente organizados de acuerdo a un criterio personal, en este caso, de los guionistas referidos por Truffaut. La ecuación incluye la constante presencia de determinado estereotipo de personajes, el tratamiento de alguna temática en particular, así como una construcción similar de los diálogos en la amplia obra de estos guionistas (Truffaut, 2008, p. 13). En síntesis, la tradición de calidad se encuentra conformada por una serie de recursos narrativos y temáticos que se repiten, de manera constante, en la obra del realizador.
Si bien Truffaut desarrolla con mayor atención el caso particular de Aurenche y Bost, también da cabida a que ciertos directores puedan ser ubicados dentro de esta tradición de calidad, entre los que menciona a Jean Renoir, Robert Bresson, Jean Cocteau, Abel Gance y Max Ophüls, y otros $(2008, \text { p. 16 })^{2}$. El cineasta y crítico hace hincapié, al enlistar a estos realizadores dentro de esta clasificación, que la mayoría de ellos también desempeñaron la labor de guionistas en la mayoría de sus filmes, siendo artífices ta nto de la historia primigenia como de la puesta en escena de la misma sin alguna mediación industrial de por medio.

En este primer paso dado por Truffaut en lo que vendría a convertirse como la teoría del cine de autor, es posible apreciar un predominio de la narración —o historia- sobre la técnica cinematográfica, puesto que únicamente toma en consideración elementos característicos del guion como lo podrían ser la construcción de los personajes, los diálogos, así como la temática o problemática desarrollada en las películas de estos realizadores y guionistas mencionados en su ensayo. Elementos que, al repetirse constantemente en la obra de sus creadores, vendrían a conformar la tradición de calidad.

André Bazin (1918-1958), uno de los miembros fundadores de Cahiers du Cinéma, continuó el debate en torno a la autoría en el cine partiendo del texto de Truffaut. En su ensayo "De la Politque des Auteurs", publicado en el número 70 (1957) de la misma revista, Bazin comienza a presentar algunas críticas o comentarios a lo apuntado por Truffaut. En primera instancia, considera precipitado reflexionar que un filme, por el simple hecho de haber sido realizado por un destacado director - con el sello de tradición de calidadno pueda ser de mala calidad o inferior a los demás. Para Bazin, el filme o la obra debe ser capaz de trascender a la figura del director (2008, p. 20); es decir, gozar de cierta independencia dentro de la filmografía del creador. De esta manera, se podrían reconocer obras de inferior calidad en el

\footnotetext{
${ }^{2}$ La selección que realiza Truffaut de qué cineastas pueden situarse bajo el sello de la tradición de calidad se encuentra basada en la ambición de las producciones cinematográficas, así como en el reconocimiento de la crítica, como bien expresa al inicio de su ensayo "Una cierta tendencia del cine francés": "Si bien los cineastas franceses realizan un centenar de películas cada año, de todos es sabido que sólo diez o doce merecen el interés de los críticos y los cinéfilos, el interés, por tanto, de estos Cahiers. Estas diez o doce películas constituyen lo que se ha llamado la tradición de la calidad; debido a su ambición despiertan la admiración de la prensa extranjera y defienden dos veces al año los colores de Francia en Cannes y en Venecia, donde, desde 1946, obtienen con bastante regularidad medallas, leones de oro y grandes premios" (Truffaut, 2008, p. 9).
} 
acervo de un prestigioso director o una buena película creada por un cineasta sin una gran trayectoria o prestigio de por medio.

Bazin continúa analizando y matizando los postulados de Truffaut centrando su atención en la libertad creativa que los cineastas destacados deben poseer al escribir $\mathrm{y}$ dirigir sus propias historias. Si bien Truffaut presentaba esto como el mejor escenario en el que podrían desarrollarse los realizadores, Bazin menciona que es complicado que el director dé rienda suelta a sus intereses artísticos y creativos, puesto que debe, al mismo tiempo, adaptarse y adecuarse a las corrientes y necesidades del momento particular (Bazin, 2008, p. 22).

A pesar de aproximarse cautelosamente al tema, Bazin no descalifica o nulifica la existencia de una politque de auteurs a la que define, sintéticamente y con reservas, como la acción de elegir o considerar "el factor personal en la creación artística como un estándar de referencia, y luego asumir que continúa e, incluso, progresa de una película a otra" (Bazin, 2008, p. 25). Dentro de este "factor personal" al que hace referencia Bazin, es posible encontrar, nuevamente, un predominio del ámbito narrativo sobre el técnico en lo que se refiere a los elementos que el director repite a lo largo de su filmografía. En este caso menciona que las coincidencias y constantes yacen en los juicios morales presentes en las cintas, así como en los personajes y en la acción representada (2008, p. 25).

El esbozo de estas ideas y diálogos en torno a la autoría provenientes de los cineastas y críticos más reconocidos de la prestigiosa revista francesa tuvo sus ecos en el resto del mundo, sobre todo en la industria estadounidense, que recibió de buena forma la existencia de un sello personal que un cineasta dota a su obra, viendo en esta una posibilidad de beneficiar económicamente a la industria, situación que trajo consigo considerables cambios al sistema de producción y el papel que ocupaba el director. Gracias a estas ideas que sustentaban el papel del cineasta como autor y al hecho de que: "Eran capaces de ganar dinero a través del control de la realización y la expresión personal, los estudios comenzaron a darles a sus directores mayor control sobre sus películas después de la década de 1950. Debido a este cambio en toda la industria, la teoría del autor comenzó a evolucionar con la industria misma" (Tregde, 2013, p. 7).
Hasta el momento se han revisado dos aproximaciones al concepto de autoría dentro del séptimo arte, ambas provenientes de Francia y enmarcadas en el movimiento crítico-cinematográfico de Cahiers du Cinéma. Por su parte Truffaut habla de una tradición de calidad por parte de algunos guionistas y realizadores franceses, mientras que Bazin define la existencia de u na politique des auteurs en donde ciertas peculiaridades narrativas se repiten y encuentran presentes en la obra de algunos directores. Ni Truffaut ni Bazin hablan, directamente, de una teoría del cine de autor, sino de tendencias o fenómenos presentados, con mayor frecuencia, en el cine francés.

El encargado de la denominación y del confinamiento de estas aproximaciones bajo el título distintivo de la teoría del cine de autor, fue el crítico de cine estadounidense Andrew Sarris (1928-2012). En su ensayo "Notas sobre la teoría del autor en 1962", publicado en el número 29 de la revista Film Culture (1962), Sarris esquematizó lo tratado anteriormente en Cahiers du Cinéma - a la vez que lo adaptó al contexto norteamericano, siendo reflejo a sí del impacto de las ideas francesas en la industria americana- en tres premisas básicas que permitirán ubicar si un cineasta puede o no ser considerado como un autor, mismas que se presentan a continuación: "La primera premisa de la teoría del autor es la competencia técnica de un director como criterio de valor [...]. Si un director no tiene competencia técnica, no tiene un talento elemental para el cine, es expulsado automáticamente del panteón del director [...]. La segunda premisa de la teoría del autor es la personalidad distinguible del director como criterio de valor. En un grupo de películas, el director debe presentar ciertas características recurrentes de estilo, mismas que sirven como su firma. La manera en que se ve y se desenvuelve una película debe tener relación con la forma en la que un director piensa y siente [...]. La tercera y última premisa de la teoría del autor tiene que ver con el significado interior, la máxima gloria del cine como arte. El significado interior se extrapola de la tensión entre la personalidad de un director y su material [...]"(Sarris, 2008, p. 43).

Estas tres premisas, en su conjunto, permitirán, según Sarris, identificar si u n c ineasta puede s er c onsiderado un autor. Como se puede apreciar, en la primera de ellas, el crítico estadounidense da cabida a un campo que había sido ignorado tanto por Truffaut como por Bazin: la técnica cinematográfica. 
Dentro de esta, Sarris toma en consideración el manejo del color, la fotografía, la música, vestuario, decoración, el guion y las actuaciones (2008, p. 43). Bajo su óptica, un realizador que no haga buen manejo de estos elementos no puede figurar como autor, puesto que se precisa una competencia técnica.

En la segunda premisa yacen los avances previos y aproximaciones realizadas por los críticos de Cahiers $d u$ Cinéma, la individualidad del cineasta debe manifestarse o hacerse presente de manera constante a lo largo de su filmografía, esto en aras de establecer el sello o el estilo que distinguirá su obra de la de los demás directores. En particular, se aprecia que Sarris retoma la idea de Bazin en lo que se refiere a que en sus películas el cineasta debe exponer su manera de ver al mundo y sus respectivos juicios morales.

Finalmente, en lo relativo a la tercera premisa propuesta por Sarris, es ahí donde se han posado numerosas críticas por parte de otros estudiosos de la teoría del autor. Si bien resulta ambigua y subjetiva en lo que se refiere al "significado interior", desde la óptica de Sarris, puesto que no desarrolla lo suficiente esta idea, se puede entender que el significado interior se halla una vez que el cineasta es capaz de dejar su huella o fijar su personalidad en un material que no fue concebido por él mismo; es decir, cuando trabaja con un guion o una idea no propia.

Pauline Kael (1919-2001) en su ensayo "Circles and Squares," publicado en la revista Film Quarterly (1963), critica el hecho de que Sarris haya incluido esta tercera premisa en su texto sin aclarar que únicamente podía aplicarse para cineastas que trabajaran con guiones ajenos, debido a que, en una primera lectura, se da a entender que un director-guionista queda inmediatamente descalificado de recibir el título de autor, ya que no se presenta esta confrontación entre su personalidad y su material de trabajo que permitirá descifrar el significado interior al que se refiere el crítico estadounidense (Kael, 2008, p. 53). ${ }^{3}$

Desde la perspectiva de Sarris, es preciso que un director cumpla con las tres premisas para que pueda ser considerado un autor, el cumplimiento de una o dos le conferirá un nombramiento diferente como se aprecia a continuación: "Las tres premisas de la teoría del autor pueden visualizarse como

${ }^{3} \mathrm{Kael}$, frecuentemente, se oponía a las ideas de Sarris con respecto a la teoría de autor y criticó a este que, según sus escritos, las mujeres cineastas no podían aspirar a ocupar el puesto de "autor". tres círculos concéntricos: el círculo externo corresponde a la técnica; el círculo intermedio al estilo personal; y el círculo interno al significado interior. Los roles correspondientes del director pueden ser designados, de esta manera, como técnico, estilista y autor"(Sarris, 2008, p. 43).

"Notas sobre la teoría del autor en 1962" es, posiblemente, uno de los textos sobre la autoría en el cine que goza de mayor alcance a nivel internacional, alcance que se evidencia en la misma abundancia de otras obras que parten de las ideas y premisas presentadas por Sarris, ya sea para complementarlas, comentarlas o criticarlas.

Dentro de las voces que parten de la teoría de Sarris para desarrollar las propias, figura el académico canadiense Graham Petrie (1939), quien en su texto "Alternatives to Auteurs", publicado en 1973 en la revista Film Quarterly, se propone reconfigurar las categorías o títulos bajo los cuales puede situarse el cineasta, más allá del concepto de autor. De esta manera idea un modelo bajo el cual identifica tres posibles vías de identificar al cineasta: "Creadores: Aquellos que, en todas o en la mayoría de sus películas, pudieron llevar a cabo todas o la mayoría de las siguientes funciones: escribir, elegir o colaborar cercanamente con el guion; haber podido decidir en la elección de los actores y técnicos implicados; dirigir; producir o trabajar de manera cercana con el productor; editar o supervisar la edición de la versión a estrenarse de la cinta [...]. Inadaptados, rebeldes, desafortunados y profesionales: Aquellos que tuvieron el control lo suficientemente a menudo como para poder identificar en algunas de sus películas una muestra de coherencia y continuidad artística. Sin embargo, en etapas importantes de su carrera, realizaron un trabajo puramente rutinario [...]. Ladrones de escena y armonizadores: Esta categoría no se limita únicamente a los directores, sino que incluye a cualquier colaborador destacado en una película cuya influencia parece haber sido decisiva para dotar a la obra de calidad e impacto duradero [... ${ }^{4}$ Estas personas rara vez tenían un control artístico total sobre los filmes y su influencia sólo es evidente en algunas de las películas en las cuales trabajaron" (Petrie, 2008, pp. 115-117).

Más allá de buscar ampliar o desplazar las premisas propuestas por Sarris, Petrie plantea este esquema alterno para demostrar que existen otras vías alternas al estudio del "factor

\footnotetext{
${ }^{4}$ En este rubro Graham Petrie destaca la presencia de actrices como Greta Garbo o Bette Davis.
} 
personal en la realización de películas que las propagadas por la teoría del autor y la suposición común de que se debe comenzar por el director cuando se trata de determinar la calidad o valor de una película en particular" (Petrie, 2008, p. 117).

Así como es posible identificar u na línea constante en las aproximaciones y construcciones teóricas-críticas en torno al cine de autor como una posible vía de estudiar la obra de algunos cineastas y realizadores, figura otro bloque importante de textos y estudios que analiza los problemas que se desprenden de la utilización de esta tanto en el análisis como en la crítica cinematográfica.

El mismo Andrew Sarris señaló que la utilización de la teoría del cine de autor sin la debida investigación y análisis, podía degenerar en la práctica esnob que se asocia a la comercialización de pinturas basándose únicamente en el nombre del artista y no en la obra por sí misma (2008, p. 37). En esta misma línea, el crítico de cine británico Victor Francis Perkins (1936-2016) da a entender en su libro Film as Film: Understanding and Judging Movies (1972) que el hecho de que una cinta haya sido realizada por un cineasta con completa libertad creativa para expresar sus ideas en su obra — retomando aquí ciertas ideas de la tradición de calidad de Truffaut-, no asegura, siempre, un buen resultado o una película de calidad (Perkins, 2008, p. 68).

Otro apunte importante a la teoría del cine de autor proviene de la misma crítica al estructuralismo, siendo el teórico y cineasta londinense Peter Wollen (1938-) una de sus principales voces. En su libro Signs and Meaning in the Cinema (1972), considera que la búsqueda de repeticiones, semejanzas y constantes en la obra de un cineasta resulta insuficiente. E n c ambio, p ropone q ue $\mathrm{t}$ ambién $\mathrm{s}$ e tomen en cuenta las diferencias y oposiciones presentes entre las producciones, asegurando que los textos pueden "ser estudiados no sólo por su universalidad (lo que tienen todos en común), sino también por su singularidad (lo que los diferencia de los demás)" (Wollen, 2008, p. 60).

Con ciertas consonancias con las ideas de Kael respecto a la teoría del cine de autor, Roland Barthes, desde el campo de la lingüística, reniega por completo de la existencia del autor en su texto "La muerte del autor", al asegurar que "tan pronto se narra un hecho [...] la voz pierde su origen, el autor se encamina a su propia muerte, la escritura comienza" (1977, p. 142), siendo el lenguaje quien habla ahora, no el autor (p. 143).

Barthes considera que la búsqueda del autor en una obra, es un recurso implementado por la crítica, a manera de atajo o vía sencilla, para explicar y entender el texto. Sin embargo, asegura que "dotar de un autor a un texto es imponerle un límite al texto ${ }^{5}$, amueblarlo con un significado final, cerrar el escrito" (1977, p. 147). De ahí que para que se pueda hablar del nacimiento de un lector, sea necesaria la muerte del autor (p. 148).

Las ideas de Kael, junto con lo enunciado por Barthes con respecto a la "muerte del autor" pueden ser consideradas como un reflejo de la visión posmoderna con respecto a la teoría del autor, una teoría que se ciñó al desarrollo del cine moderno: "La posmodernidad no desea valorar la posición del director como un gran autor, pues el arte es de todos y para todos. La premisa del cine moderno era idolatrar la genialidad del director masculino como autor único e indiscutible de un filme, y a la vez valorar al cine como un arte" (Gutiérrez Correa, 2014, p. 16).

La propuesta de Barthes no marca el find e los cuestionamientos alrededor de la identificación de un cineasta como un autor, sino que puede ser considerada como una de las aristas tomadas por la teoría con respecto al tema. En las últimas décadas y en años recientes, el debate de la autoría ha continuado vigente y dando pie a nuevas concepciones partiendo de los mismos cambios en la industria cinematográfica y al nacimiento de las plataformas de streaming.

Entre las propuestas teóricas más recientes figura la planteada por David Kipen en su obra — misma que podría considerarse un manifiesto- $T$ he $S$ chreiber $T$ heory: $A$ Radical Rewrite of American Film History (2006). En ella, el autor propone una revaloración del puesto del escritor, guionista, en la historia del cine estadounidense, considerándolo como un personaje sumamente importante en el proceso de producción cinematográfica, cuyo puesto ha sido ensombrecido y silenciado por los estudios, críticas y aproximaciones teóricas que se concentran únicamente en el director. Bajo su óptica, el guionista podría considerarse el

\footnotetext{
${ }^{5} \mathrm{Si}$ bien Barthes en este ensayo se inclina hacia la literatura, la reflexión realizada por el teórico francés puede aplicarse también a los estudios visuales $\mathrm{y}$ al cine mismo.
} 
arquitecto del filme, mientras que el director y el resto del crew podrían considerarse, respectivamente, como el capataz y los trabajadores de la construcción.

Otra propuesta de índole reivindicativa proviene de Paul Sellors en su artículo Collective Authorship in Film (2007), donde sostiene que, dadas las peculiaridades del cine, resulta más preciso hablar de la existencia de una autoría colectiva que de una individual. En cierto modo, Sellors pretende reconocer por igual a todos los miembros implicados en una producción — directores, guionistas, productores, actores, maquillistas, fotógrafos, editores, estudios, etc.- como autores de una obra en donde sus respectivos trabajos se ven plasmados en conjunto, como una parte de un todo.

Finalmente, el surgimiento y consolidación de las plataformas de streaming se encuentra orientando los estudios y debates sobre la autoría hacia nuevos rumbos. Grosso modo, se podría hablar de la existencia predominante de dos situaciones con respecto al papel del autor frente al contenido creado para estos espacios de exhibición doméstica: 1) el ocultamiento y ensombrecimiento de la figura del director - o creador en el caso de las series- bajo el sello de la plataforma de streaming (bajo las leyendas "Una serie original de Netflix", "Amazon Original”, entre otras). ${ }^{6}$ 2) La generación de contenidos y guiones a partir de algoritmos que aseguran, en la mayoría de los casos, la complacencia de los espectadores, tomando como base el mismo consumo audiovisual de la audiencia. En este último caso, el director se convierte, junto con su equipo, en el encargado de unir los elementos, arquetipos, géneros cinematográficos, situaciones sugeridos por los mismos algoritmos; es decir, en un realizador on demand.

Como se ha podido apreciar a través de este breve recorrido por las principales obras teóricas y críticas centradas en la teoría del cine de autor, no existe un modelo o metodología de estudio carente de críticas, mejoras o matices, situación que puede deberse al mismo hecho de que se busca hacer objetivo y estable (un modelo de análisis) lo que por esencia es subjetivo y variable (la obra y mentalidad de un cineasta). Al mismo tiempo, se han podido apreciar los cambios que experimentan los postulados con el mismo paso

\footnotetext{
${ }^{6}$ Una dinámica similar a lo que ha ocurrido con el cine de animación estadounidense desde sus orígenes.
}

del tiempo y el surgimiento de nuevas tendencias o prácticas de consumo audiovisual.

A continuación se procederá a realizar un análisis a la trayectoria cinematográfica d el d irector j aponés Hayao Miyazaki bajo la hipótesis de que la obra de este cineasta puede situarse bajo el sello del cine de autor. Para demostrar esto, se retomarán los tres postulados expuestos por Andrew Sarris que fueron desarrollados en este apartado, bajo los cuales será confrontada la obra del realizador. De igual manera se ampliarán las tres premisas de Sarris tomando en consideración los textos e ideas de Truffaut, Bazin, así como las críticas de Kael y Petrie, teniendo cabida tanto las ideas modernas como posmodernas en torno a la autoría cinematográfica.

Cabe señalar que, en aras de acotar el estudio, dentro de la filmografía a analizar de Miyazaki, únicamente se tomarán en cuenta los largometrajes y películas, no cortometrajes ni series televisivas, pese a que en estos productos audiovisuales también es posible identificar el sello autoral del realizador japonés. $^{7}$

\section{Entre obsesiones y subjetividades}

Al momento de hablar del anime y del cine de animación en general, resulta indispensable fijar 1 a a tención e $n$ los estudios Ghibli, los cuales han sido la casa de importantes proyectos fílmicos como El viaje de Chihiro (Sen to Chihiro no kamikakushi, 2001), El increíble castillo vagabundo (Hauru no ugoku shiro, 2004), La leyenda de la princesa Kaguya (Kaguyahime no monogatari, 2013) y, recientemente, La tortuga roja (La tortue rouge, 2016); todas estas cintas han sido capaces de superar las fronteras geográficas de la industria de la animación cinematográfica, logrando competir en certámenes internacionales, destacando tanto por su calidad técnica, como por la historia narrada en las respectivas diégesis.

Los estudios Ghibli fueron fundados en 1984, siendo Hayao Miyazaki (1941), Isao Takahata (1935-2018) y Toshio Suzuki (1948) sus fundadores. Los dos primeros se convirtieron en las imágenes más reconocidas del estudio de animación japonés gracias a los filmes que escribieron y

\footnotetext{
${ }^{7}$ La decisión de excluir series televisivas y cortometrajes busca acotar el de por sí ya amplio corpus de análisis de la obra de Miyazaki.
} 
dirigieron durante las últimas décadas del siglo $\mathrm{XX}$, mientras que Suzuki se ha desempeñado como productor de varios proyectos cinematográficos.

En el caso particular de Hayao Miyazaki, se trata de un director nacido el 5 de enero de 1941, en Tokio, en una familia con buena situación económica. Su padre y su tío se encontraban a cargo de un negocio encargado de la fabricación de timones para aviones de guerra. Por otra parte, Miyazaki tenía una estrecha relación con su madre, a la cual admiraba profundamente. Estudió Ciencias Políticas y Económicas en la Universidad de Gakushuin, en donde formó parte de un club de lectura que lo hizo apasionarse por la literatura occidental (Robles, 2013a, p. 10).

En 1963, Miyazaki comienza a laborar en TOEI Animation, donde da sus primeros pasos dentro de la animación y en donde conoce a Isao Takahata, con quien entabla una profunda amistad que los lleva a trabajar juntos en múltiples proyectos en varios estudios y en la misma fundación de los estudios Ghibli unas décadas después.

En la actualidad, Hayao Miyazaki cuenta con 11 largometrajes dentro de su filmografía, así como múltiples proyectos televisivos. Para el presente artículo se tomarán en consideración las siguientes producciones cinematográficas: El castillo de Cagliostro (Rupan sansei: Kariosutoro no shiro, 1979), Nausicä̈, guerreros del viento (Kaze no tani no Naushika, 1984), El castillo en el cielo (Tenkû no shiro Rapyuta, 1986), Mi vecino Totoro (Tonari no Totoro, 1988), Kiki entregas a domicilio (Majo no takkyûbin, 1989), Porco Rosso (Kurenai no buta, 1992), La princesa Mononoke (Mononoke-hime, 1997), El viaje de Chihiro, El increíble Castillo Vagabundo, Ponyo, el secreto de la sirenita (Gake no ue no Ponyo, 2008) y Se levanta el viento (Kaze tachinu, 2013).

Retomando el modelo del cine de autor propuesto por Andrew Sarris, la primera premisa corresponde a la competencia técnica que debe poseer un director para poder ingresar al primero de los círculos concéntricos que lo conducen al grupo selecto de los autores. En el caso particular de Hayao Miyazaki, se le ha reconocido internacionalmente su valía como artista y como cineasta.

Los estudios Ghibli se desarrollaron en un momento crucial de la historia del cine de animación, puesto que a finales de los noventa e i nicios del siglo XXI s e d io la transición al cine digital. Para la animación, esto significaba - al menos para los estudios que se propusieron seguir a las nuevas tecnologías — dejar atrás las vías “artesanales" para la creación de sus filmes para adoptar, en su lugar, la utilización de computadoras y demás recursos que simplificaban, de manera considerable, el proceso creativo.

Hayao Miyazaki, al igual que varios miembros del estudio Ghibli, se han mostrado renuentes a la incorporación de la tecnología digital dentro de su esquema de trabajo. Sin embargo, poco a poco han ido cediendo ante los adelantos tecnológicos permitiendo aquellos que, bajo su perspectiva, no atentan contra el trabajo creativo de los realizadores, quienes continúan — como bien se aprecia en el documental Yume to kyôki no ôkoku (2013) de Mami Sunada ${ }^{8}$ — trabajando a mano cada una de las escenas y personajes de sus creaciones.

El director y guionista de El viaje de Chihiro incorporó algunos recursos de la tecnología digital en esta cinta por primera vez, sobre todo en lo que se refiere a $1 \mathrm{~m}$ anejo y ajuste del color, así como en el movimiento de algunos de los personajes. En sus filmes posteriores, Miyazaki continuó manteniendo el balance entre la labor artesanal y la animación digital, tal y como se aprecia en El increíble Castillo Vagabundo, donde se utilizó la tecnología 3D para el diseño del castillo en movimiento y en Ponyo, el secreto de la sirenita, donde el cineasta decidió utilizar sólo la animación digital para "colorear" el filme (Robles, 2013b, p. 96).

Tanto en el documental Yume to kyôki no ôkok como en las memorias del mismo Hayao Miyazaki — Starting Point, 1979-1996 y Turning Point, 1997-2008 - se hace evidente la preocupación del cineasta japonés por cuidar el mínimo detalle en la creación de sus filmes. Gracias a su minuciosa participación tanto en el guion, como en el proceso de elección de los actores de doblaje, en la dirección, en la edición y su estrecha relación con los productores - a veces Takahata, otras Suzuki-; Miyazaki podría situarse en la categoría de creador esbozada por Petrie. De igual manera su obra, así como los componentes de la misma enunciados en este párrafo, demuestran la calidad y la competencia técnica requerida en la primera premisa de la teoría del cine

${ }^{8}$ El documental de Mami Sunada se centra en acompañar a Hayao Miyazaki y a Isao Takahata en su proceso creativo, durante la creación de los filmes Se levanta el viento y La princesa Kaguya, respectivamente. 
de autor de Andrew Sarris. Al mismo tiempo, Miyazaki muestra apego y un gran manejo de los elementos del lenguaje cinematográfico (imagen, sonido, montaje, puesta en escena y narración) en cada una de sus producciones. $\mathrm{Su}$ competencia técnica ha sido reafirmada tanto por la crítica cinematográfica, las audiencias y numerosos académicos que ven en él un referente en la técnica de la animación y la misma narrativa audiovisual (Robinson, 2011; Robles, 2013; Greenberg, 2018).

Pasando a la segunda premisa de Sarris, esta dialoga en torno a la personalidad del cineasta y de su peculiar estilo, elementos que deben encontrarse presentes en la mayor parte de sus obras al grado de poder ser considerados como un sello o firma d istintiva d e 1 a fi lmografía del realizador. Dentro de esta premisa tienen cabida las ideas y aproximaciones tanto de François Truffaut como de André Bazin en torno a la presentación de obsesiones, juicios morales y personajes-estereotipos recurrentes en las películas de un director; es decir, elementos que forman parte del ámbito narrativo o del mundo representado en la cinta (diégesis).

Al realizar una revisión de los 11 largometrajes de Hayao Miyazaki es posible encontrarse con la presencia de cinco elementos narrativos y temáticos recurrentes en su producción audiovisual, mismos que pueden ser señalados como recursos estilísticos que dotan a su obra de un sello característico y personal, al provenir, directamente, de su experiencia de vida, sus obsesiones y subjetividades. Se trata de la representación de personajes femeninos empoderados o en puestos de poder; la construcción de personajes ambivalentes u oscilantes en lo que se refiere a su moralidad; el énfasis en un mensaje de carácter ambientalista que a menudo versa en la idea de que el ser humano está terminando con el mundo; la presentación constante de escenas de vuelo y maquinarias voladoras; así como la presencia de una narrativa afín al subgénero cinematográfico del coming of age.

En lo que se refiere a la representación de las mujeres en su cine, es posible hablar de la generación de un esquema propio de Miyazaki que se sustenta en la presencia recurrente y constante de mujeres con carácter fuerte, que tienden a ser las protagonistas y las heroínas de sus largometrajes, situación que podría ser considerada como un eco distante de la estrecha relación del cineasta con su madre: "Mucho se ha remarcado a lo largo de su dilatada trayectoria la destacada presencia de la mujer en la filmografía de Hayao Miyazaki en roles poco habituales en el mundo del cine y, concretamente, en la animación. Acostumbrados a las inevitables comparaciones con Disney o Pixar — comprensibles porque hay que poner un baremo, pero en el fondo absurdas-, desde luego, la mujer en los trabajos de Miyazaki destaca, y él mismo quiere destacarla. No hay que olvidar que proviene de una cultura tradicionalmente machista como es la japonesa, por lo que el papel de la mujer en sus películas es aún más llamativo. Consciente de la desigualdad que existe entre hombres y mujeres, Miyazaki crea un prototipo de personaje femenino con unas cualidades muy claras: ellas son fuertes, valientes, decididas, inteligentes... pero no perfectas, por suerte, porque las haría poco creíbles. También tienen su punto de inocencia, sus dudas y una bondad que, a veces, las pone en apuros"(López Martín y García Villar, 2015, p. 21).

En cada una de sus 11 películas, es posible encontrarse con, al menos, un personaje que cumpla con este esquema de representación femenina. De igual manera más allá del carácter fuerte e independiente de las mujeres de sus tramas, es común que estas ocupen papeles de mando dentro de los mundos cinematográficos, c omo p odría ser el caso de Nausicaä — princesa y líder de su pueblo_ en Nausicä̈, guerreros del viento; la lideresa de los piratas en El castillo en el cielo; la Dama Eboshi — gobernadora de un poblado dedicado a la fundición del hierro- en $\mathrm{La}$ princesa Mononoke; o las brujas Yubaba y Zeniba en El viaje de Chihiro.

Otra cualidad distintiva del cine de Hayao Miyazaki es la constante presencia de personajes con una moralidad ambivalente; es decir, en la obra de este realizador es posible encontrarse a personajes que jamás podrán ser considerados completamente como los villanos o los héroes de la historia. Los personajes de Miyazaki tienen y revelan por igual sus virtudes y defectos, situación que — al igual que en el caso de la representación femenina-, tiende a hacerlos más humanos $\mathrm{y}$, por lo tanto, reales ante el espectador.

Esta situación se aprecia de manera más clara en aquellos personajes de Miyazaki que son presentados, en primera instancia, como antagonistas dentro de sus respectivas diégesis. Conforme se desarrolle la trama, el espectador, junto con los protagonistas, irá descubriendo que el personaje que otrora se consideraba el villano dentro de la cinta, también 
cuenta con sus virtudes y, sobre todo, con una justificación a sus actos. Tal es el caso del personaje de Kushana en Nausicä̈, guerreros del viento, una princesa que invade junto con sus tropas el Valle del Viento, asesinando al padre de Nausicaä, la protagonista. La inesperada irrupción de Kushana y la conquista a los moradores del valle se explicará posteriormente en la trama, revelando que la expedición buscaba recuperar la carga de una aeronave que podría ayudar a frenar el avance del Mar de la Decadencia y la subsecuente extinción de la humanidad. Dentro de los actos de la princesa se aprecia una buena intención, en donde será preciso el sacrificio de unos cuantos individuos en búsqueda de un bien superior.

Una situación similar se aprecia en La princesa Mononoke, en donde el personaje de la Dama Eboshi desarrolla dos facetas principales a lo largo de la diégesis: 1) una que la presenta como una mujer belicosa y 2) otra en la que es vista como una mujer comprensiva y misericordiosa; ambas facetas en un perfecto balance a lo largo de la cinta. Así como la Dama Eboshi es capaz de combatir ferozmente con samuráis o los espíritus del bosque, también expone su vida al cuidar de manera directa a una comunidad de leprosos. Estos son sólo dos casos de la ambivalencia moral de los personajes de Hayao Miyazaki, mismos que permiten ejemplificar esta constante en la filmografía del cineasta japonés.

La naturaleza y la preservación de la misma forman parte constitutiva de la obra de Hayao Miyazaki, pudiendo identificar en gran parte de sus largometrajes algún mensaje que invita, ya sea directa o subliminalmente, al espectador a cuidar del medio ambiente. Esta situación se evidencia con mayor claridad en las cintas Nausicä̈, guerreros del viento y La princesa Mononoke, ambas producciones se sitúan en un mundo distópico en el que el ser humano lucha por su supervivencia en un entorno inhóspito e insalubre, en donde la naturaleza - a manera de esporas venenosas, hordas de insectos y deidades asociadas a la flora y fauna- busca recuperar el mundo que alguna vez le perteneció.

Asimismo, en otras películas de Miyazaki apartadas de las distopías y de los panoramas apocalípticos, se presenta este mensaje ambientalista de manera más sutil. Como podría ser el caso de El castillo en el cielo, donde el mundo occidental industrializado contrasta con el mágico castillo en donde la naturaleza se desarrolla libremente y permite la vida de flora y fauna; o también lo presentado en Ponyo, el secreto de la sirenita donde se plantea una crítica subliminal a la pesca y a la contaminación marina en una escena en donde la protagonista, Ponyo, queda atrapada en una red junto con peces y basura.

La reiteración de esta temática pro-naturaleza en la filmografía de Hayao Miyazaki es equiparable a lo que Bazin se refiere como la presencia de juicios morales compartidos entre el cineasta y lo expuesto en su obra. El interés del realizador japonés por la preservación del medio ambiente va más allá de los mundos ideados por su imaginación, esto se hace evidente mediante la creación del Totoro Forest Project, una campaña de recaudación de fondos para la preservación de bosques y áreas verdes en Japón, misma que fue creada y promovida por el mismo Miyazaki (Robles, 2013a, p. 44).

El vuelo y las aeronaves son otra de las obsesiones personales de Hayao Miyazaki que, constantemente, se manifiesta en su filmografía, pudiendo ser relacionada con el hecho de que su padre y su tío trabajaron en un negocio dedicado a la fabricación de timones para aviones de guerra.9 En diez de los 11 filmes del realizador japonés es posible encontrarse con la presencia de una escena de vuelo, ya sea en aviones, avionetas, escobas o en dragones. De igual manera, dos de sus largometrajes centran su trama en personajes fuertemente vinculados con el vuelo, siendo este el caso de Porco Rosso, donde se presenta la historia de un piloto de la Segunda Guerra Mundial que fue transformado en cerdo, y de Se levanta el viento, filme con tintes biográficos centrado en la vida de Jiro Horikoshi, un ingeniero aeronáutico vinculado con la creación de aviones de guerra.

Las peculiaridades del subgénero cinematográfico conocido como coming of age han sido incorporadas por Hayao Miyazaki a un número considerable de sus producciones, pudiendo considerarlas, ya, como otro sello distintivo fácilmente identificable en su obra. Las obras que se ubican bajo esta clasificación se caracterizan por la presencia de problemáticas afines o relacionadas con la transición de una etapa de la vida a otra (como lo podría ser el paso de la niñez a la adolescencia o de la adolescencia a la adultez). Por lo regular, el personaje principal se siente inseguro o incapaz

\footnotetext{
${ }^{9} \mathrm{El}$ interés de Hayao Miyazaki en las aeronaves se evidencia, también, en el mismo nombre dado al estudio fundado por él, Takahata y Suzuki. Ghibli significa, en italiano, "viento arenoso" y, de igual manera, un avión utilizado durante la Segunda Guerra Mundial para volar sobre el Sahara recibe el nombre de Caproni Ca. 309 Ghibli.
} 
de hacer frente a lo que le espera ahora que iniciará una nueva etapa de su vida, por lo cual emprende una lucha contra sus miedos e inseguridades - ya sea real o metafóricamentesaliendo, casi siempre, triunfante habiendo adquirido la seguridad y madurez requeridas para dar el siguiente paso en su vida.

Miyazaki recupera esta dinámica dentro de los arcos dramáticos de sus diferentes personajes en varios de sus filmes. Mientras que las hermanas Satsuki y Mei deben acostumbrarse a una nueva vida en el campo y lejos de su madre enferma e internada en un hospital en $\mathrm{Mi}$ vecino Totoro, la joven bruja Kiki debe dejar atrás a su familia para independizarse en una comunidad completamente ajena y desconocida para ella en Kiki entregas a domicilio.

Dentro de esta recuperación del coming of age, el cineasta japonés acostumbra acompañar el viaje interior de sus protagonistas hacia la madurez con otro viaje de carácter externo y físico. Tal podría ser el caso de las repentinas mudanzas y traslados a los que se enfrentan Satsuki y Mei en Mi vecino Totoro o Chihiro en El viaje de Chihiro; así como la mágica transformación de la joven Sofî en una anciana que inicia una aventura en El increíble castillo vagabundo.

La transformación tanto física como mental que experimenten los personajes de Hayao Miyazaki en su particular apropiación del coming of age deja en claro al espectador que estos han dado un paso importante en su vida adquiriendo aquello que les hacía falta para continuar adelante, en cierto modo jamás volverán a ser la misma persona que eran al inicio del filme.

La profundización en estas cinco cualidades o características temáticas y narrativas de la filmografía de Hayao Miyazaki ha permitido explorar y vincular la obra del realizador con el concepto de personalidad distinguible a la cual se refiere Sarris en la segunda premisa de su modelo del cine de autor, pudiendo considerarlas como la firma del director o el sello característico que inserta en sus cintas. En sus películas, Miyazaki impregna su ideología, sentir personal, cosmovisión, preocupaciones, inquietudes, intereses $\mathrm{y}$, sobre todo, elementos muy personales, pudiendo considerarlos como autobiográficos.

Finalmente, resta tratar la tercera y última premisa de la teoría del cine de autor que gira en torno al significado interior, el cual proviene de la tensión entre la personalidad de un director y el material con el cual trabaja. Si bien bajo la crítica realizada por Pauline Kael a esta premisa, no podría analizarse la obra de Hayao Miyazaki puesto que el mismo director funge como guionista de sus filmes, al analizar las peculiaridades de la mayoría de las obras que conforman la filmografía d el r ealizador j aponés sí es p osible identificar el resultado proveniente de la tensión entre la personalidad del director y el material utilizado, como se desarrollará a continuación.

La ópera prima de Miyazaki, El castillo de Cagliostro fue un proyecto encomendado al realizador; es decir, no concibió por sí mismo la idea presentada en la cinta ni decidió, por su propia cuenta, adaptar la serie manga creada por Kazuhiko Kato. Esto último no impidió que Miyazaki impregnara de su peculiar estilo y elementos referidos con anterioridad en este texto a una historia ajena durante el proceso de adaptación del manga al cine.

En las siguientes películas del cineasta japonés se aprecia la denominada libertad creativa en donde Miyazaki, ya dentro de los estudios Ghibli, elige qué historias quiere llevar a la gran pantalla, ya sean propias o provenientes de alguna obra literaria. En el caso de Nausicä̈, guerreros del viento, el filme s e e ncuentra $b$ asado e $\mathrm{n}$ e $1 \mathrm{~m}$ anga $\mathrm{i}$ deado $\mathrm{p}$ or el mismo realizador y publicado, periódicamente, en la revista Animage. El hecho de que Miyazaki adaptara una historia propia y proveniente de su imaginación — siendo así director y guionista - no implica la ausencia de la tensión entre el director y su material, una tensión que puede ser expresada a través del traslado de un soporte impreso a uno audiovisual: "La producción de la película fue ardua y extenuante para los implicados, puesto que debían crear una historia comprensible por sí misma con su respectivo inicio, desarrollo y desenlace; puesto que el manga apenas llevaba 16 capítulos publicados $\mathrm{y}$, por lo tanto, la trama no se había cerrado todavía. Al mismo tiempo, el periodo de producción fue de nueve meses, un rango bastante ajustado para un proyecto de animación artesanal"(Ortega Mantecón, 2018, p. 189).

Otras situaciones en la obra de Miyazaki que revelan la tensión entre el director y su material que terminan evidenciando el significado interior concebido por Sarris, se aprecian en los casos en donde el cineasta recupera algunos elementos narrativos y temáticos provenientes de 
la literatura occidental para incorporarlos — con sus debidas modificaciones y adaptaciones - a su imaginario y universo, elementos que podrían encontrarse dentro del campo de la intertextualidad.

Por mencionar algunos ejemplos de esto, se puede hablar de la recuperación de algunos elementos de Los viajes de Gulliver (Gulliver's Travels, 1726) en El castillo en el cielo, como lo podría ser el nombre de Laputa para referirse al castillo volador; los nexos y similitudes entre Las crónicas de Narnia (The Chronicles of Narnia, 1950) y Alicia en el país de las maravillas (Alice's Adventures in Wonderland, 1865) con Mi vecino Totoro; la influencia del cuento La sirenita (The Little Mermaid, 1837) de Hans Christian Andersen en Ponyo, el secreto de la sirenita; o la misma vida del ingeniero aeronáutico Jiro Horikoshi en Se levanta el viento.

Además de El castillo de Cagliostro, en la filmografía de Miyazaki es posible encontrarse con dos filmes que cuentan con sustento literario, específicamente en novelas, mismas que el cineasta decidió adaptar por su cuenta a manera de adaptaciones libres dando el debido crédito a la historia primigenia. Este es el caso de Kiki entregas a domicilio y El increíble castillo vagabundo, filmes en los que posiblemente resulta más evidente hallar la tensión entre el cineasta y su material de trabajo (la novela) que conduce al significado interior y, a la vez, al círculo interno del postulado de Sarris.

\section{Conclusión}

La teoría del cine de autor es un campo en los estudios del séptimo arte sobre el que se ha debatido constantemente. Desde los teóricos y cineastas de Cahiers du Cinéma, hasta críticos y académicos de diferentes nacionalidades, han presentado sus diferentes visiones y concepciones acerca de lo que convierte a un director de cine en autor.

En el presente texto se hizo uso del modelo propuesto por Andrew Sarris, tomando en consideración las ideas de François Truffaut, André Bazin, Pauline Kael y Graham Petrie, para demostrar que el cineasta japonés Hayao Miyazaki puede situarse en el grupo de directores considerados autores bajo esta óptica o criterio. Esto mediante la identificación en su filmografía de la competencia técnica; la personalidad o sello característico otorgado a sus creaciones; así como el significado interior que se extrapola de la tensión existente entre la personalidad de un director y su material de trabajo. Siendo así, uno de los pocos cineastas centrados en la técnica de la animación que puede enmarcarse dentro del cine de autor.

Hayao Miyazaki, en sus 11 largometrajes, ha sido capaz de imprimir en su obra un sello o firma característica de su personalidad, de su historia de vida, de sus obsesiones, aficiones, pasatiempos y, sobre todo, de la manera en que ve y concibe al mundo; todos estos elementos, temáticas o recursos narrativos que permiten conocer, con lujo del detalle, al autor detrás de la obra.

\section{Referencias}

Barthes, R. (1977). Image, Music, Text. Londres: Fontana Press.

Bazin, A. (2008). De la Politique des Auteurs. En B.K. Grant (Ed.), Author and Authorship. A Film Reader (pp. 19-28). Oxford: Blackwell Publishing.

Grant, B.K. (2008). Introduction. En B.K. Grant (Ed.), Author and Authorship. A Film Reader (pp. 1-6). Oxford: Blackwell Publishing.

Greenberg, R. (2018). Hayao Miyazki. Exploring the Early Work of Japan's Greatest Animator. Nueva York: Bloomsbury Academic.

Gubern, R. (2005). Prólogo. En J.D. Sanderson (Ed.), ¿Cine de autor? Revisión del concepto de autoría cinematográfica (pp. 15-19). Alicante: Universidad de Alicante.

Gutiérrez Correa, M.L. (2014). El cine de autor del cine moderno al cine posmoderno. En Razón y palabra (pp. 16-24). Núm. 87, julio-septiembre.

Kael, P. (2008). Circles and Squares. En B.K. Grant (Ed.), Author and Authorship. A Film Reader (pp. 46-54). Oxford: Blackwell Publishing.

Kipen, D. (2006). The Schreiber Theory: A Radical Rewrite of American Film History, Hoboken: Melville House Pub.

López Martín, A. y García Villar, M. (2015). Mi vecino Miyazaki. Madrid: Diabolo Ediciones.

Miyazaki, H. (2014a). Starting Point. 1979-1996. San Francisco: VIZ Media.

Miyazaki, H. ( 2014b). Turning Point. 1997-2008. San Francisco. VIZ Media.

Ortega Mantecón, A. (2018). Los insectos sobrevuelan el Mar de la Decadencia, el futuro según Miyazaki. En A. Ortega (Coord.), Cuando el futuro nos alcance. Utopías 
y distopías en el cine (pp. 187-200). México: Notas Universitarias.

Perkins, V.F. (2008). Direction and Authorship. En B.K. Grant (Ed.), Author and Authorship. A Film Reader (pp. 65-75). Oxford: Blackwell Publishing.

Petrie, G. (2008). Alternatives to Auteurs. En B.K. Grant (Ed.), Author and Authorship. A Film Reader (pp. 110-118). Oxford: Blackwell Publishing.

Roberts, S. (2018). Miyazaki the Auteur. California: Shane Roberts.

Robinson, J.M. (2011). The Cinema of Hayao Miyazaki. Maidstone: Crescent Moon Publishing.

Robles, M. (2013a). Antología del Studio Ghibli. De Nausicaä a Mononoke (1984-1997). Mallorca: Manga Books. Robles, M. (2013b). Antología del Studio Ghibli. De los Yamada a Kokuriko (1999-2011). Mallorca: Manga Books.

Sarris, A. (2008). Notes on the Auteur Theory. En B.K. Grant (Ed.), Author and Authorship. A Film Reader (pp. 35-45). Oxford: Blackwell Publishing.

Sellors, P. (2007). Collective Authorship in Film. En The Journal of Aesthetics and Art Criticism (pp. 263-271), $65(3)$.

Tredge, D. (2013). A Case Study on Film Authorship: Exploring the Theoretical and Practical Sides in Film Production. En The Elon Journal of Undergraduate Research in Communications (pp. 5-15), 4(2).

Truffaut, F. (2008). A Certain Tendency of the French Cinema. En B.K. Grant (Ed.), Author and Authorship. A Film Reader (pp. 9-18). Oxford: Blackwell Publishing.

Wollen, P. (2008). The Auteur Theory. En B.K. Grant (Ed.), Author and Authorship. A Film Reader (pp. 55-64). Oxford: Blackwell Publishing.

\section{Filmografía}

Dudok de Wit, M. (Director) y Suzuki, T. Sorlat, G. Père, O. Caucheteux, P. (Productores). (2016). La tortuga roja. Japón Francia Bélgica: Prima Linea Productions, Studio Ghibli, Arte France Cinéma y Wild Bunch

Miyazaki, H. (Director) y Katayama, T. (Productor). (1979). El castillo de Cagliostro. Japón: Tokyo Movie Shinsha.

Miyazaki, H. (Director) y Takahata, I. (Productor). (1984). Nausicä̈, guerreros del viento. Japón: Nibariki, Tokuma Shoten, Hakuhodo y Topcraft.

Miyazaki, H. (Director) y Takahata, I. (Productor). (1986). El castillo en el cielo. Japón: Nibariki, Studio Ghibli y Tokuma Shoten.

Miyazaki, H. (Director) y Hara, T. (Productor). (1988). Mi vecino Totoro. Japón: Tokuma-Shoten, Studio Ghibli y Nibariki.

Miyazaki, H. (Director) y Miyazaki, H. (Productor). (1989). Kiki entregas a domicilio. Japón: Nibariki, Studio Ghibli, Tokuma Shoten y Yamato Transport.

Miyazaki, H. (Director) y Suzuki, T. (Productor). (1992). Porco Rosso. Japón: Japan Airlines, Nibariki, Studio
Ghibli, TNNG, Toho Company, Tokuma Shoten y Nippon Television Network.

Miyazaki, H. (Director) y Suzuki, T. (Productor). (1997). La princesa Mononoke. Japón: DENTSU Music and Entertainment, Nibariki, Studio Ghibli, TNDG, Tokuma Shoten y Nippon Television Network.

Miyazaki, H. (Director) y Suzuki, T. (Productor). (2001). El viaje de Chihiro. Japón: Studio Ghibli.

Miyazaki, H. (Director) y Suzuki, T. (Productor). (2004). El increíble castillo vagabundo. Japón: Studio Ghibli, Nippon Television Network, DENTSU Music and Entertainment y Tokuma Shoten.

Miyazaki, H. (Director) y Suzuki, T. (Productor). (2008). Ponyo, el secreto de la sirenita. Japón: Studio Ghibli, Dentsu, Nippon Television Network y Toho Company.

Miyazaki, H. (Director) y Suzuki, T. (Productor). (2013). Se levanta el viento. Japón: Studio Ghibli, Nippon Television Network y Toho Company.

Takahata, I. (Director) y Nishimura, Y. Ujiie, S. (Productores). (2013). La leyenda de la princesa Kaguya. Japón: Studio Ghibli, Dentsu, Nippon Television Network y Toho.

Sunada, M. (Directora) y Kawakami, N. (Productor). (2013). Yume to kyôki no ôkoku. Japón: Dwango y Ennet. 